\title{
Calibration of local earthquake magnitudes in Nepal
}

\author{
*S. Rajaure, B. P. Koirala, M. Bhattarai, P. L. Shrestha, S. Maske, \\ D. R. Tiwari, and U. Gautam \\ Department of Mines and Geology, Lainchaur, Kathmandu, Nepal \\ (*Email:srajaure@yahoo.com)
}

\begin{abstract}
An attempt has been made to calibrate magnitudes of local earthquakes recorded by National Seismological Centre (NSC) of the Department of Mines and Geology (DMG), Nepal with other magnitudes of corresponding earthquakes reported by International Seismological Centre (ISC), UK, and United States Geological Survey (USGS), USA. Local magnitudes (ML) are used from NSC, corresponding surface wave magnitudes (Ms) and body-wave magnitudes (Mb) are used from catalog of ISC and moment magnitude (Mw) is used from catalog of the USGS.
\end{abstract}

\begin{abstract}
After regression analysis, it has been found that the local magnitudes (ML) reported by NSC are slightly larger than Ms, Mb and $\mathrm{Mw}$ in all cases. ML, on average, is larger by an amount of about 0.5 , than Ms; with an uncertainty of 0.7 . Similarly, ML is larger than corresponding $\mathrm{Mb}$ by an amount of about 0.6 and the uncertainty is about 0.5 . Likewise, ML is larger than Mw by about 1.0 and the corresponding uncertainty is 0.7
\end{abstract}

Keywords: Local magnitude, body wave magnitude, surface wave magnitude, moment magnitude

Received: 5 January 2011

\section{INTRODUCTION}

The Himalayan Range is a seismically active belt in the world, which has repeatedly produced large and destructive earthquakes in the past (Chitrakar and Pandey 1986, Bilham 1995). In the last century the Himalaya has produced four great earthquakes (Pandey et al. 1999, Fig. 1) which destroyed parts of the region killing a large number of population. Region in the west of Kathmandu and east of Dehradun (India) has not produced any great $(\mathrm{M}>8.0)$ earthquake since approximately last 500 years (Bilham et al. 1995, Pandey et al. 1999) and has been termed as a 'Central Himalayan Seismic Gap' (Khattri 1987, 1992).

National Seismological Centre (NSC) of Department of Mines and Geology (DMG), Nepal has been operating a nationwide network of short period (vertical component) seismic stations since 1995. Departement Analyse Surveillance Environnement (DASE), France has been cooperating with DMG in the installation, maintenance and upgrading of the network. Monitoring of seismicity in Nepal has revealed a continuous and narrow belt of microseismic activity that runs all along the Himalaya. The microseismic events are occurring at the front of the Himalaya in response to interseismic straining of upper part of crust (Pandey et al. 1995, 1999). Majority of the earthquakes are shallow focus earthquakes $(10 \mathrm{~km}<$ depth $<25 \mathrm{~km})$. Relatively deeper earthquakes are observed in the epicentral area of 1988 Udayapur Earthquake, where the earthquakes occurred in the lower crust to upper mantle (depth $>55.0 \mathrm{~km}$; Dikshit and Koirala 1991, Chen and Zhaohui 2004). revision accepted: 10 May 2011

Nepal Himalaya has repeatedly experienced destructive earthquakes in the past. The 1833-North Kathmandu Earthquake (M7.8), 1934-Bihar Nepal Earthquake (M8.2) (Pandey et al. 1988), and 1988-Udayapur Earthquake (M 6.5, Dikshit and Koirala 1991) are some of the recent destructive earthquakes which occurred in Nepal. Bilham et al. (1995) and Bilham and Ambraseys (2004) have pointed out the possibility of great earthquake in the west of Kathmandu which has not produced great earthquake, possibly, since 1505 .

Earthquake magnitudes are measures of relative sizes of earthquakes (Lay and Wallace 1995). There are a number of magnitude scales, which are Local Magnitude $(\mathrm{ML})$, Body Wave Magnitude (Mb), Surface Wave Magnitude (Ms) and Moment Magnitude (Mw) (Table 1). The measurement of ML, Mb and Ms is based on the maximum trace of amplitude and period of the recorded seismic wave. $\mathrm{Mw}$ is the direct measurement of energy released during an earthquake and is preferred over other types of magnitudes. An earthquake catalog containing a uniform size estimate is important for long-term seismic hazard assessment (Braunmiller et al. 2005). NSC calculates and reports ML for local earthquakes which occur at distance less than $1000 \mathrm{~km}$. However, to homogenize earthquake magnitudes; magnitude calibration is usually carried out. Additionally, in seismic hazard assessment $\mathrm{Mw}$ is preferred to other magnitude scales because $\mathrm{Mw}$ represents the energy more accurately. Therefore, other kinds of magnitudes are usually converted into moment magnitude before we can use them in hazard 


\section{S. Rajaure et al.}

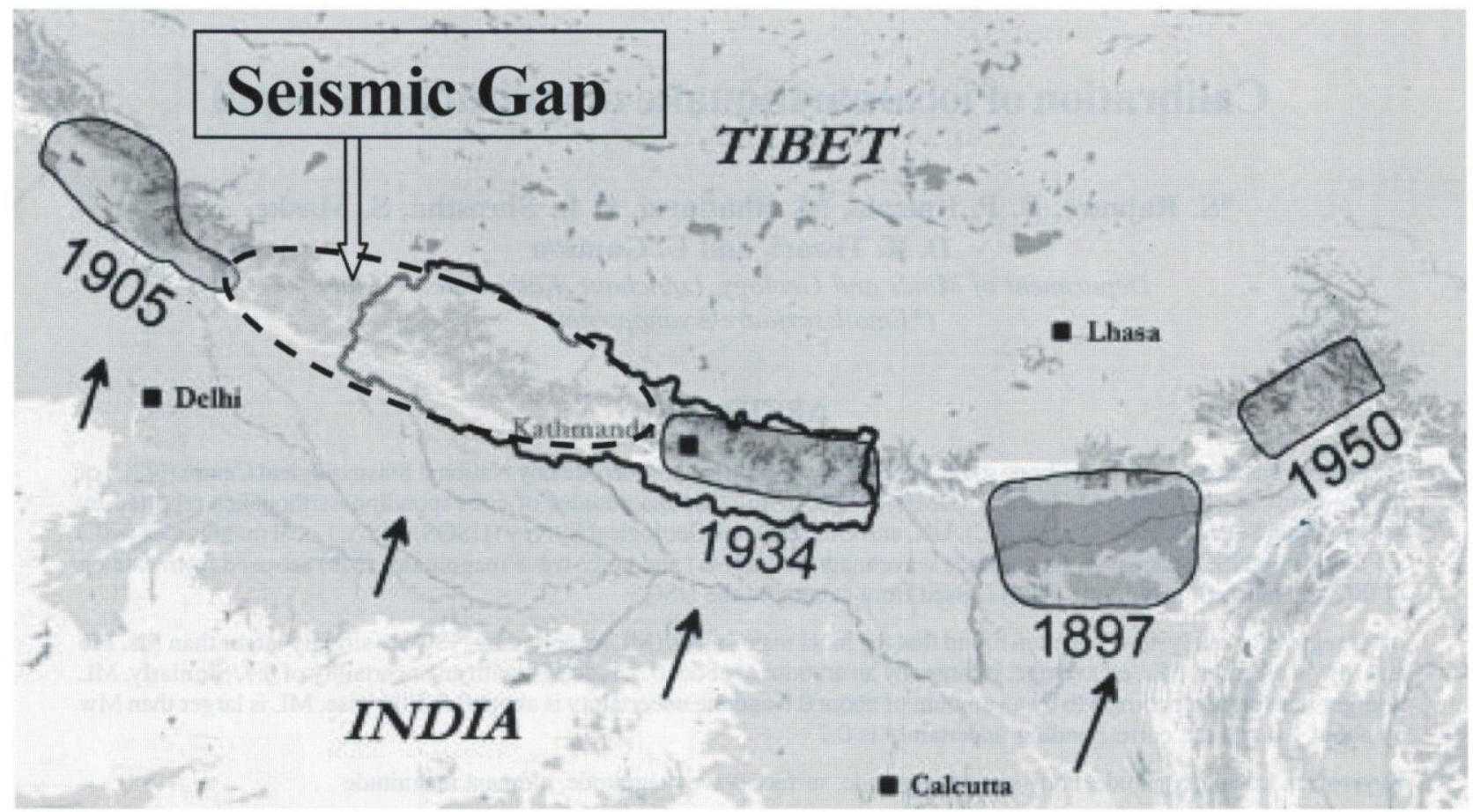

Fig. 1: Historical, great earthquakes which occurred in the Himalaya in the last century. Region between 1905 Kangra Earthquake (Mw 7.8) and 1934 Bihar-Nepal Earthquake (Mw 8.2) has not produced any great (Mw>8.0) earthquake since the last 500 years and stands as a seismic gap (modified from Pandey et al. 1999)

Table 1: Data selected for the regression analysis

\begin{tabular}{|c|c|c|c|c|c|}
\hline Magnitude & Number & Minimum & Maximum & Mcan & Std. Dev \\
\hline $\mathrm{ML}$ & 622 & 4.3 & 7.3 & 4.8 & 0.65 \\
\hline $\mathrm{Ms}$ & 162 & 3.20 & 5.1 & 4.40 & 0.50 \\
\hline $\mathrm{Mb}$ & 622 & 6.6 & 7.1 & 4.3 & 0.40 \\
\hline $\mathrm{Mw}$ & 25 & 4.7 & 6.6 & 5.29 & 0.48 \\
\hline
\end{tabular}

assessment. These days, catalog data is collected from several networks to produce combined catalog that requires calibration of different kinds of magnitude scales.

\section{OBJECTIVES}

In Nepal, NSC reports magnitude of local earthquakes on ML scale. There was a necessity of calibration of ML with other magnitude scales using as much as possible data. The main objectives of this study are to carry out three calibration studies between (i) ML and Mb, (ii) ML and Ms, and (iii) ML and Mw of earthquakes which occurred in or around Nepal and to establish relation between ML and other kinds of magnitudes.

\section{PREVIOUS WORKS}

Magnitude calibration studies have been carried out in other countries, where different types of magnitudes are available depending up on the types of instruments used by networks. While updating the earthquake catalog of Switzerland, Faeh et al. (2003) addressed the question of homogeneous earthquake size. Ristau et al. (2003) calibrated the ML and Mw of earthquakes of the west coast of Canada. They converted the ML into the Mw using regression analysis and found that the ML is systematically smaller than Mw by 0.5 . Similarly, Ristau et al. (2003) studied the ML and Mw in Canada in order to produce homogenized and consistent catalog. Moment magnitudes are now possible in Canada down up to 4. The study has found that Mw are systematically overestimated than ML at least by 0.5 .

Pandey et al. (2002) studied the relation between ML and Ms of local earthquakes, which occurred in Nepal and in the adjacent region. The study was carried out for the seismic hazard map of Nepal. The authors have used earthquakes from Nepal and its adjoining region along the Himalaya. Pandey et al. (2002) established a relation between the ML and Ms, which is given below.

$$
\mathrm{Ms}=0.6329 \mathrm{ML}+1.0316
$$




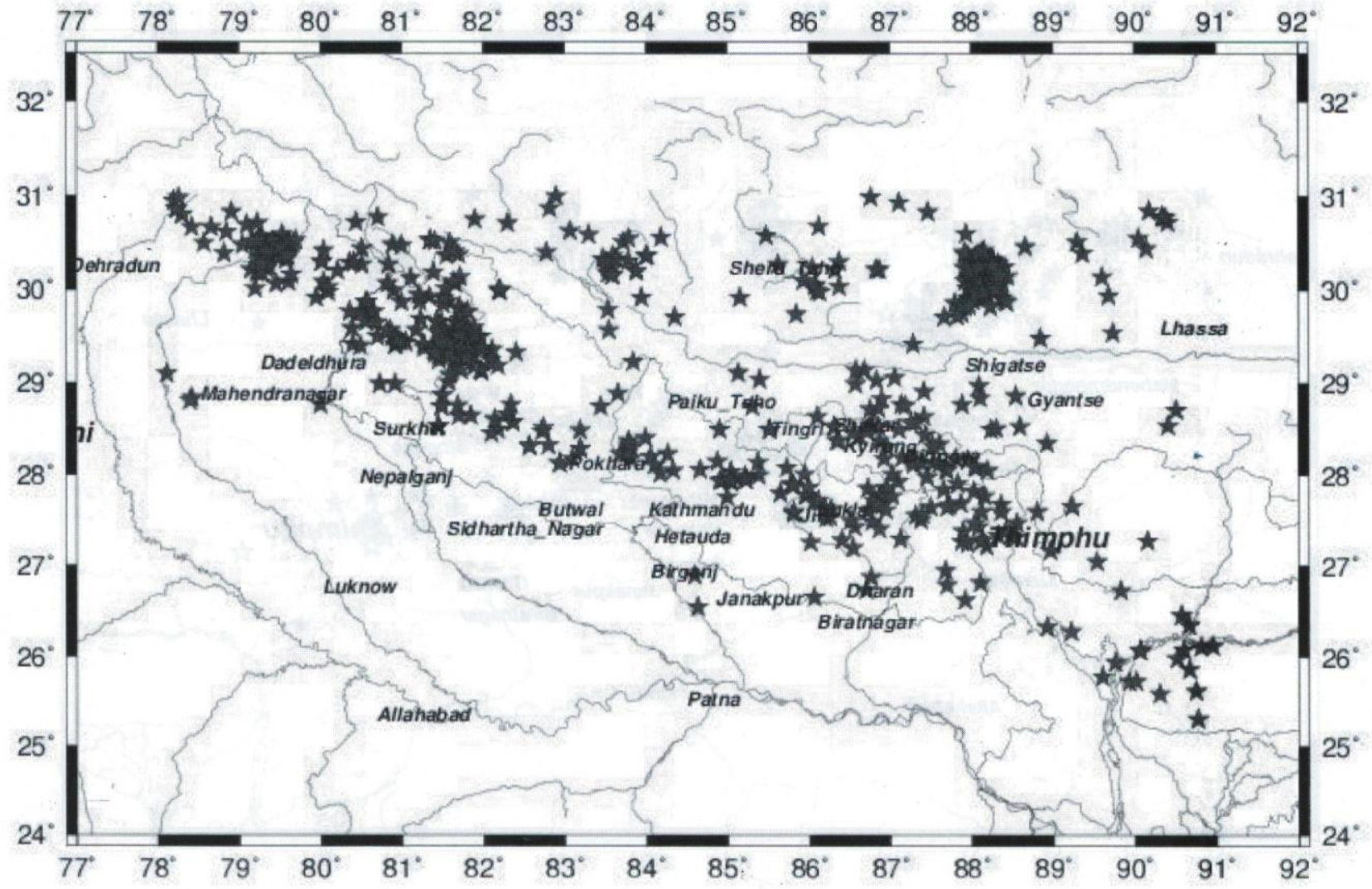

Fig. 2: Earthquakes (solid black stars) selected for the study of Mb and ML. The number of earthquakes is 622.

\section{DATA SELECTION}

In this study, four different types of magnitudes of corresponding local earthquakes, occurred in and around Nepal are collected. Such data are collected from the catalog of NSC (Nepal), ISC (UK), and USGS (USA). The local magnitudes are collected from earthquakes occurred from the Indo-Gangetic Plain in the south to the South Tibet in the north, where both geology and tectonic environment are quite different. The Himalaya is formed in compressional environment whereas the South Tibet is developed in extensional environment.

The number of collected $\mathrm{Mb}$ is 622 (Fig. 2) and that of Ms is 162 (Fig. 3). The Ms and Mb are collected from ISC corresponding to ML recorded by NSC. The number of available $\mathrm{Mw}$ is very small in comparison to that of the $\mathrm{Mb}$ and Ms. Moment magnitudes (Mw) are collected from USGS. The characteristics of the data are presented in Table 1.

\section{Calibration of different magnitudes}

Regression analysis has been carried out to calibrate different magnitudes of earthquakes which occurred in and around Nepal. Fig. 4 presents the regression analysis of the $\mathrm{Mb}$ and ML. The distribution of the $\mathrm{ML}$ and $\mathrm{Mb}$ is scattered above $M L=6.0$. After regression analysis the following relation (equation 2) between the ML and $\mathrm{Mb}$ was created. Statistically, ML is slightly larger than the $\mathrm{Mb}$ by about 0.6 .

$$
\mathrm{Mb}=0.396 * \mathrm{ML}+2.1401
$$

The standard deviation of $\mathrm{Mb}$ is 0.40 and that of ML is 0.6 . Where $\mathrm{Mb}$ is body wave magnitude and $\mathrm{ML}$ is local magnitude of earthquakes. This relation can be used to convert ML into $\mathrm{Mb}$ or $\mathrm{Mb}$ into ML from different catalogs to make a consistent catalog of homogenized magnitudes.

The regression analysis of the ML and Ms is presented in Fig. 5. Note that the data scatters above ML 6.0. The following relation (equation 3) is established after the regression analysis between ML and Ms. In this case also ML is slightly larger, on average, than Ms by 0.6 .

$$
\mathrm{Ms}=0.6055 * \mathrm{ML}+1.4794
$$

Where Ms is surface wave magnitude and ML is local magnitude. The standard deviation in Ms is 0.5 and that of ML is 0.65 . This equation can be used to convert ML reported by NSC into Ms. 


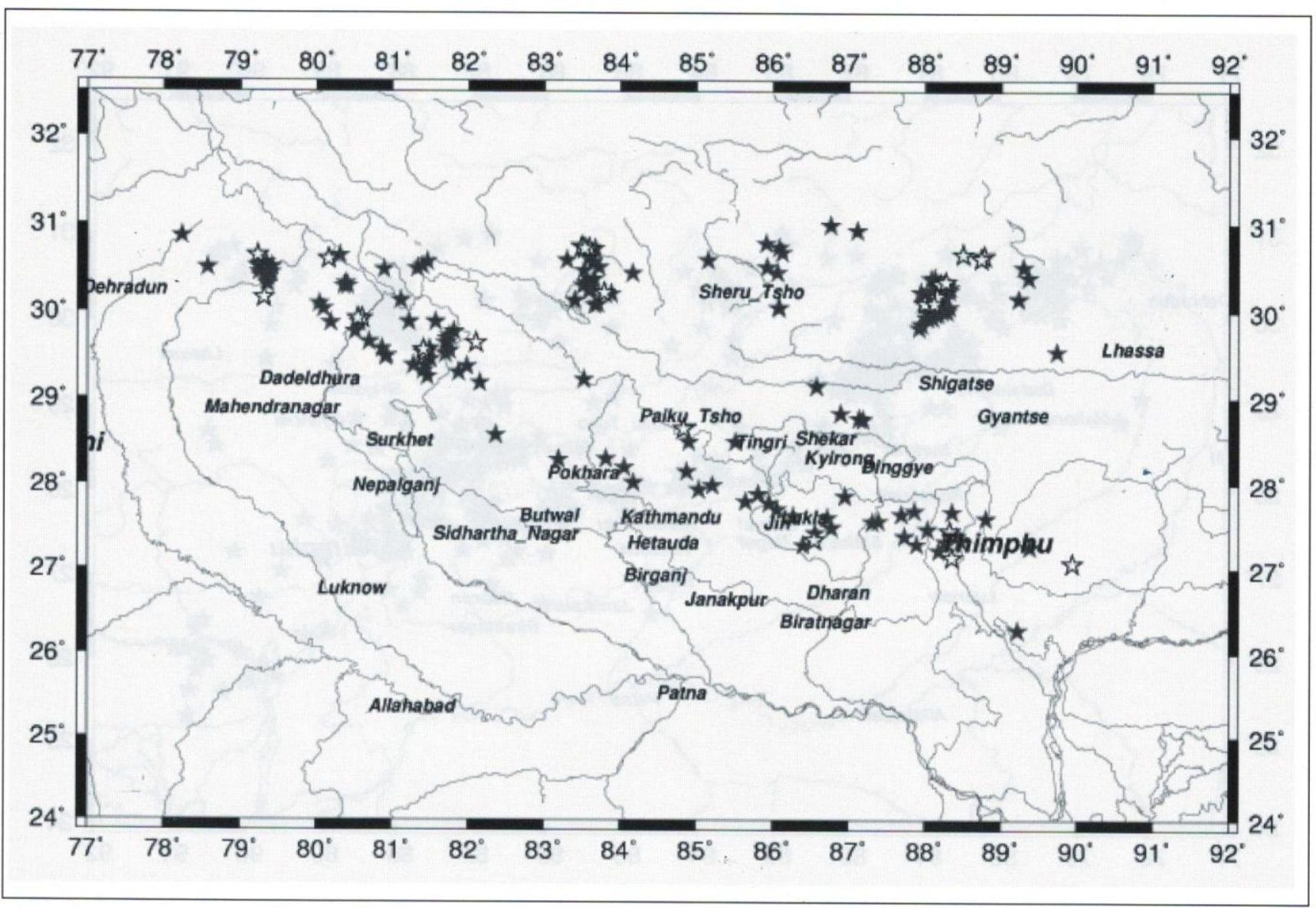

Fig. 3: Earthquakes (black stars) selected for the study of the Ms and ML. The number of earthquakes is 162. The open stars represent the Mw used in ML Mw analysis.

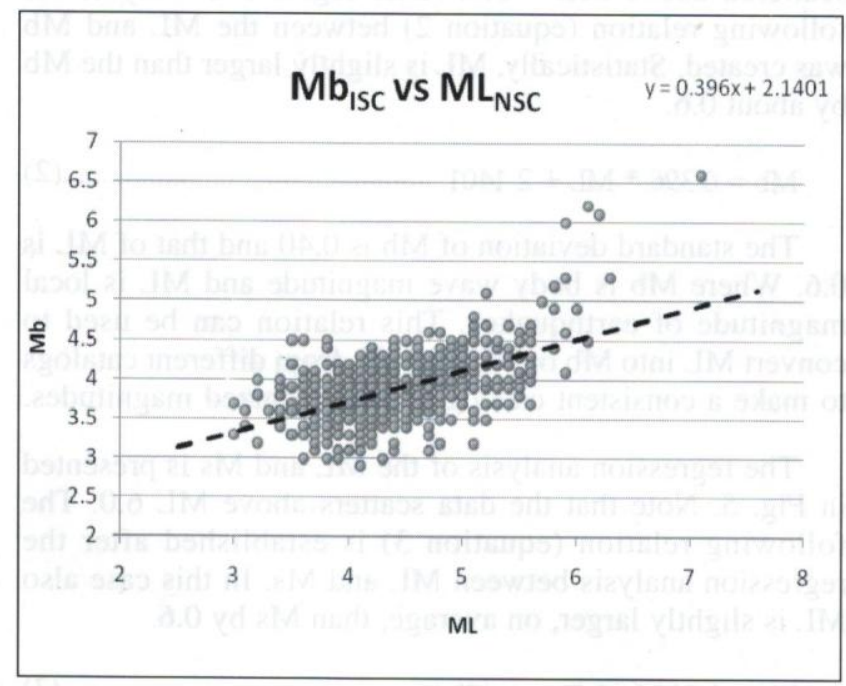

Fig. 4: Comparison between body wave magnitude $(\mathrm{Mb})$ and local magnitude (ML). ML is slightly larger than corresponding Mb. Above $M L=6$, the data is scattered.

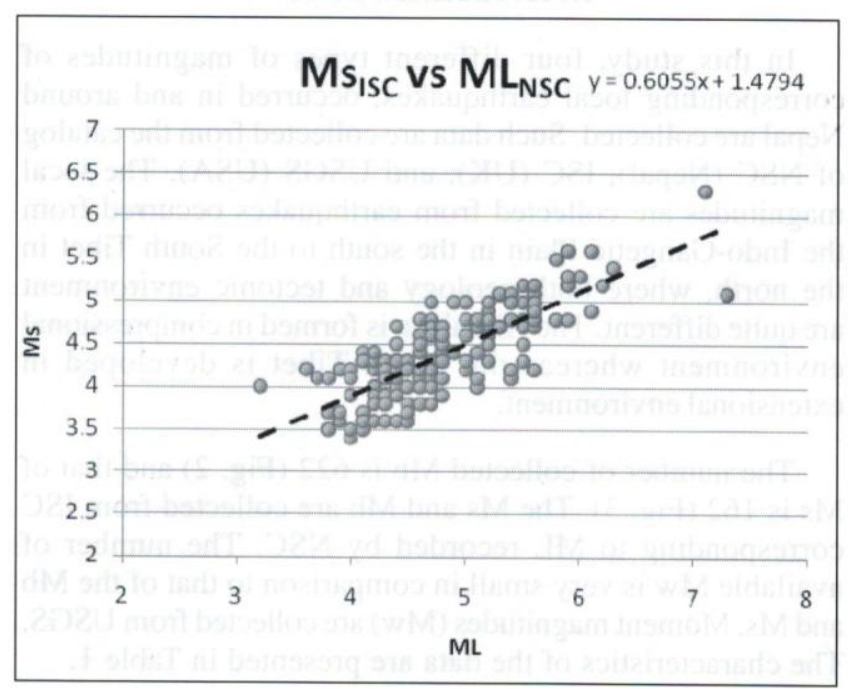

Fig. 5: Comparison between Ms and ML. ML is slightly larger than Ms. 


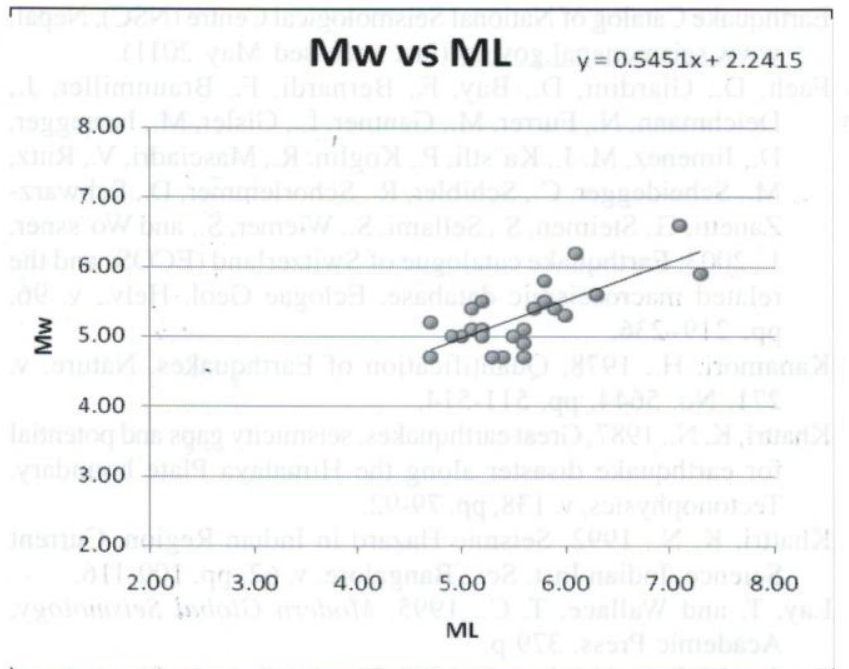

Fig. 6: Comparison between ML and Mw. The number of data is very small (25) relative to the number of $\mathrm{Mb}$ and Ms. In this case also $\mathrm{ML}$ is larger in comparison to $\mathrm{Mw}$ by about 0.7 .

The number of Mw is very small (Fig. 3) in comparison to that of $\mathrm{Mb}$ and Ms. Regression analysis of the data results in the following relation (equation 4). Fig. 6 presents the regression analysis of $\mathrm{ML}$ and $\mathrm{Mw}$.

$$
\mathrm{Mw}=0.5451 * \mathrm{ML}+2.2415
$$

\section{DISCUSSIONS}

Magnitude calibration is important in disaster management of any region where magnitudes are not available in required scale. Moment magnitude is preferred to other magnitude scales to derive seismic parameters required in seismic hazard assessment of any region as it is more robust and represents whole spectrum of energy released during an earthquake. NSC, Nepal reports earthquake magnitudes on ML, which requires its calibration with $\mathrm{Mb}, \mathrm{Ms}$ and $\mathrm{Mw}$, so that it could be used in seismological studies and seismic hazard assessment respectively.

Large number of $\mathrm{Mb}$ in comparison to the numbers of Ms and Mw were used but, in the case of Mw, the number is very small (25). Regression analysis of $\mathrm{ML}$ and $\mathrm{Mb}$ depicts that the relation seems to be better between ML 3 and 6 whereas the data is little above ML $=6$ and is scattered too. Similarly, the study of ML and Ms also shows the similar results as observed in the case of ML and Mb. Possibly two different relations would evolve each one for $\mathrm{ML}-\mathrm{Mb}$ and ML-Ms, for magnitude above $\mathrm{ML}=6$.

Regular update of such study is necessary to refine the calibration results between different magnitudes so that the results (ML vs. Ms and ML vs. Mw) could be better constrained and used in seismic hazard assessment more confidently. The results of this calibration study (ML vs. Mw or ML vs. Ms) are expected to be helpful for conversion of the ML into Mw or Ms. If required Ms can be converted into Mw using the equations 5 and 6 (Ambrasseys 2000, Kanamori 1978), but the relations shall incorporate triple uncertainties (ML vs. Ms + Ms vs. Mo + Mw vs. Mo), where Mo is seismic moment of the earthquake. Data, after such a conversion can be used to estimate earthquake recurrence relationships required in probabilistic seismic hazard assessment. The results of this research will be used in next step in seismic hazard assessment of Nepal.

$$
\log \left(M_{0}\right)=19.08+\mathrm{Ms}
$$

Where Mo is seismic moment and Ms is surface wave magnitude.

$$
\mathrm{Mw}_{\mathrm{w}}=(2 / 3) \log (\mathrm{Mo})-10.73
$$

Where Mo is seismic moment, $\mathrm{Mw}$ is moment magnitude and $\mathrm{Ms}$ is surface wave magnitude.

The relation between the ML and $\mathrm{Mb}$ does not have much significance in seismic hazard assessment, but it can be used to convert past earthquakes from the catalog of ISC and USGS, which occurred in the region prior to the monitoring of local earthquake in Nepal, by NSC, so that the available catalog of the ML could be extended back in the past, to some extent.

\section{CONCLUSIONS}

The calibrations between ML and Mb; ML and Ms, and ML and Mw were investigated. Regression analysis shows that ML is little larger, on average, in all calibrations. It is larger by about 0.5 than corresponding MS. Similarly, ML is larger by about 0.6 than $\mathrm{Mb}$ and than $\mathrm{Mw}$ by about 1 , respectively. In the case of ML-Mw calibration, the data is very limited for this study; however, the current result can be used for the time being. The relation between ML and Ms is comparable to that established by Pandey et al. (2002). The scattering of data possibly results from the different types of instruments and techniques used in the calculation of the magnitudes and data from different tectonic environments.

The established relations between ML and $\mathrm{Mb}$, and ML and $\mathrm{Mw}$ are good for ML from 3 to 6 . The established relations therefore, can be used for ML falling in the range between 3 and 6 . Further analysis is required for ML above 6.0 when reasonable data will be available.

\section{ACKNOWLEDGEMENTS}

The authors express their heartfelt thanks to the Department of Mines and Geology, Nepal for providing necessary data to carry out this study. Similarly, the authors express their sincere thanks to International Seismological Centre, UK and United States Geological Survey for providing required data without which this study was not 


\section{S. Rajaure et al.}

possible to bring in its current form. Likewise, the authors would like to thank all personals of National Seismological Centre of Department of Mines and Geology, who were involved in the maintenance and operation of National Seismic Network, and without their effort, the data collection could not be possible and this study would not be possible. Finally, the authors wish to express their thanks to two anonymous reviewers for providing helpful and valuable comments on a first version of the manuscript.

\section{REFERENCES}

Ambrassey, N., 2000, Reappraisal of north Indian earthquakes at the turn of $20^{\text {th }}$ century. Current Science, v. 79 , pp. 1237-1250.

Bilham, R. and Ambraseys, N., 2004, Apparent Himalayan slip deficit from the summation of seismic moments for Himalayan earthquakes, 1500-2000. Current Science, pp. 10.

Bilham, R., 1995, Location and Magnitude of the 1833 Nepal Earthquake and its Relation to the rupture zones of contiguous Great Himalayan earthquakes. Current Science, v. 69(2), pp. 155-187.

Bilham, R., Bodin, P., and Jackson, M., 1995, Entertaining a great earthquake in western Nepal. Jour. Nepal Geol. Soc., v. 11 (1), pp. 73-78.

Braunmiller, T., Deichmann, N., Giardini, D., Wiemer, S., and the SED magnitude working group, 2005, Homogeneous MomentMagnitude Calibration in Switzerland, Bull. Seismological Soc. America, v. 95, No. 1, pp. 58-74.

Chen, W. P. and Zhaohui, Y., 2004, Earthquakes beneath the Himalayas and Tibet: Evidence for strong lithospheric mantle. Science, v. 304, pp. 1949- 1952.

Chitrakar, G. R. and Pandey, M. R., 1986, Historical Earthquakes of Nepal. Jour. Nepal Geol. Soc., v. 4, No. 1, pp. 7-8.

Dikshit, A. M. and Koirala, A., 1991, Geological effects and Intensity Distribution of the Udaipur (Nepal) Earthquake of August 20, 1988. Jour. Nepal Geol. Soc., v. 7, Spec. Iss., pp. 1-17.

Earthquake Catalog of International Seismological Centre (ISC), UK. www.isc.ac.uk (last accessed May 2011).
Earthquake Catalog of National Seismological Centre (NSC), Nepal. www.seismonepal.gov.np (last accessed May 2011).

Faeh, D., Giardini, D., Bay, F., Bernardi, F., Braunmiller, J., Deichmann, N., Furrer, M., Gantner, L., Gisler, M., Isenegger, D., Jimenez, M. J., Ka“stli, P., Koglin, R., Masciadri, V., Rutz, M., Scheidegger, C., Schibler, R., Schorlemmer, D., SchwarzZanetti, G., Steimen, S., Sellami, S., Wiemer, S., and Wo"ssner, J., 2003, Earthquake catalogue of Switzerland (ECOS) and the related macroseismic database, Eclogae Geol. Helv., v. 96, pp. 219-236.

Kanamori, H., 1978, Quantification of Earthquakes. Nature, v. 271, No. 5644, pp. 511-514.

Khattri, K. N., 1987, Great earthquakes, seismicity gaps and potential for earthquake disaster along the Himalaya Plate boundary. Tectonophysics, v. 138, pp. 79-92.

Khattri, K. N., 1992, Seismic Hazard in Indian Region. Current Science, Indian Inst. Sci., Bangalore, v. 62, pp. 109-116.

Lay, T. and Wallace, T. C., 1995, Modern Global Seismology, Academic Press, 379 p.

Pandey, M. R. and Molnar, P., 1988, The distribution of intensity of the Bihar-Nepal Earthquake of 15 January 1934 and bounds on the extent of the rupture zone. Jour. Nepal Geol. Soc., v. 5, No. 1 , pp. 22-44.

Pandey, M. R., Chitrakar, G. R., Sapkota, S. N., Kafley, B., Rajaure, S., and Gautam, U., 2002, Seismic Hazard Map of Nepal. Department of Mines and Geology, Nepal, scale 1:250000.

Pandey, M. R., Tandukar, R. L. P., Lave, J. P., and Massot, J. P., 1995, Interseismic Strain Accumulation on the Himalayan Crustal Ramp, Nepal. Geophy. Res. Lett., v. 22, No. 7, pp. $751-754$

Pandey, M. R., Tandukar, R. P., Avouac, J. P., Vergne, J., and Heritier, T., 1999, Seismotectonics of the Nepal Himalaya from a local seismic network. Jour. Asian Earth Sci., v. 17, pp. 703-712.

Ristau, J., Rogers, G. C., and Casidy, J. F., 2003, Moment Magnitude - Local Magnitude Calibration for Earthquakes off Canada's West Coast. Bull. Seismological Soc. America, v. 93, No. 5, pp. 2296-2300. 